\title{
Results of esophagectomy for esophageal cancer in elderly patients: Age has little influence on outcome and survival
}

Alberto Ruol, MD, FACS, ${ }^{a}$ Giuseppe Portale, MD, ${ }^{b}$ Giovanni Zaninotto, MD, FACS, ${ }^{a}$ Matteo Cagol, MD,

Francesco Cavallin, PhD, ${ }^{\mathrm{b}}$ Carlo Castoro, MD, ${ }^{\mathrm{b}}$ Vanna Chiarion Sileni, MD, ${ }^{\mathrm{b}}$ Rita Alfieri, MD, ${ }^{\text {a }}$ Sabrina Rampado, MD, ${ }^{\mathrm{a}}$ and Ermanno Ancona, MD, FACS ${ }^{b}$

Objective: The aging of the population and a longer life expectancy have led to an increased number of elderly patients with esophageal cancer being referred for surgical treatment. The aim of this study was to assess the effects of age on the outcome of surgery for esophageal cancer at a single institution.

Methods: Perioperative outcome and long-term survival of patients at least 70 years old undergoing esophagectomy between 1992 and 2005 for cancer of the esophagus or esophagogastric junction were compared with findings in younger patients. Patients who underwent an abdominal procedure only were excluded from the analysis.

Results: The analysis considered 580 patients younger than 70 years and 159 at least 70 years old. Clinical presentation in the two groups was similar, as were postoperative morbidity and mortality, despite significant differences in perioperative risk factors. Irrespective of age, overall survival was $34 \%$ at 5 years for all patients and $37 \%$ for patients with $\mathrm{R} 0$ resection.

Conclusions: Increased experience and refinements in perioperative care explain the better results of esophagectomy in elderly patients in recent years. Short- and long-term outcomes after esophagectomy for carcinoma in patients older than 70 years are comparable with those of their younger counterparts. Advanced age per se thus should not be considered a contraindication to esophageal resection.

From the Department of Medical and Surgical Sciences, Clinica Chirurgica III, University of Padova School of Medicine, ${ }^{\mathrm{a}}$ and Istituto Oncologico Veneto (IOV-IRCCS), ${ }^{\text {b }}$ Padova, Italy.

Received for publication Sept 10, 2006; revisions received Nov 15, 2006; accepted for publication Dec 12, 2006.

Address for reprints: Giovanni Zaninotto, MD, FACS, Department of Medical and Surgical Sciences, Clinica Chirurgica III, University of Padova School of Medicine, Via Giustiniani 2, 35128 Padova, Italy (E-mail: giovanni.zaninotto@unipd.it).

J Thorac Cardiovasc Surg 2007;133:1186-92 $0022-5223 / \$ 32.00$

Copyright $\odot 2007$ by The American Association for Thoracic Surgery

doi:10.1016/j.jtcvs.2006.12.040

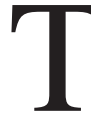
he aging of the population and a longer life expectancy have led to more elderly patients with esophageal carcinoma being referred for surgical treatment. Controversies exist concerning the effect of advanced age on the outcome of esophagectomy. There is an apparent contradiction between reports in which the individual risk of mortality after esophagectomy is strongly related to the patient's age and performance status, with worse long-term survival among elderly patients, ${ }^{1-3}$ and studies confirming improvements in the results of esophagectomy in patients 70 years old and older (mostly as a result of advances in perioperative care), with morbidity and mortality rates comparable to those in their younger counterparts. ${ }^{4-7}$ The aim of this study was to evaluate the effects of advanced age on the surgical outcome and long-term survival of patients undergoing esophagectomy for esophageal cancer at a single high-volume center.

\section{Patients and Methods}

We evaluated all patients with cancer of the esophagus or esophagogastric junction (Siewert type I-II) seen at our department between January 1992 and June 2005. Preoperative workup included physical examination, standard laboratory tests, lung function tests, and anesthesio- 
logic assessment. In selected cases, noninvasive cardiac evaluation (echocardiogram or dynamic tests to estimate ventricular function) were also performed. The American Society of Anesthesiologists classification was used to assess the operative risk. Barium swallow study and upper gastrointestinal endoscopy were performed to assess the tumor's features; flexible bronchoscopy and otolaryngologic evaluation were added for tumors of the cervical, upper, and middle esophagus. Computed tomographic scans of the chest and abdomen (and neck in selected cases) were obtained in all cases to rule out any metastatic disease. Endoscopic ultrasonography was used from 2000 onward to provide additional information on tumor depth and lymph node status.

Complete tumor resection was defined as R0, and incomplete resection with microscopic or macroscopic residual disease was defined as R1 or R2, respectively. Perioperative mortality was classed as in-hospital mortality (all deaths occurring at the hospital) and 30-day mortality (all deaths occurring within 30 days of surgery). Postoperative morbidity included any minor or major medical or surgical complications. Anastomotic leaks were recorded, both symptomatic leaks and small asymptomatic leaks detected on radiologic examination.

\section{Surgery}

Esophagectomy was performed with an Ivor-Lewis procedure, through a laparotomy and right thoracotomy, for mid to lower esophageal and esophagogastric junction tumors. A 3-stage McKeown procedure, with an additional left cervical incision, was reserved for tumors in the upper third of the esophagus. At least 6 to $8 \mathrm{~cm}$ of healthy esophagus was resected above the proximal edge of the tumor to avoid neoplastic involvement of the resection margins. In patients undergoing resection with a curative intent, en bloc lymph node dissection was performed, including the periesophageal, infracarinal, posterior mediastinal, and paracardial lymph nodes, as well as those located along the lesser gastric curvature, the origin of the left gastric artery, the celiac trunk, the common hepatic artery, and the splenic artery (with the cervical, recurrent laryngeal chains, and paratracheal nodes also resected for cancers of the cervical and upper thoracic esophagus). The alimentary tract was reconstructed immediately, preferably with the gastric pull-up technique; if the stomach was unavailable, either a jejunal loop or the left colon was used. Anastomoses were performed with a circular stapling device in the thoracic cavity and a double layer of hand-sewn running suture in the neck. For patients with cancer of the cervical esophagus, a pharyngolaryngoesophagectomy was performed.

Postoperative patient care included early extubation (preferably in the operating room), aggressive respiratory care with frequent bronchoscopic suctioning, pain control (epidural analgesia along with patient-controlled analgesia), vigorous respiratory therapy, and early mobilization and ambulation. Food intake was allowed, provided a Gastrografin swallow showed no evidence of leakage, on postoperative days 7 and 10 for stapled and hand-sewn anastomoses, respectively.

Patients were followed up routinely by their surgeons 1, 3, 6, and 12 months after the operation and every 6 to 12 months thereafter.
TABLE 1. Treatment strategies by age group

\begin{tabular}{lcc}
\hline & $\begin{array}{c}\text { Surgical } \\
\text { resection }\end{array}$ & $\begin{array}{c}\text { No surgical } \\
\text { resection* }\end{array}$ \\
\hline All patients $(\mathrm{n}=1400)$ & $764(54.6 \%)$ & $636(45.4 \%)$ \\
Patients $<70$ y $(\mathrm{n}=1045)$ & $599(57.3 \%)$ & $446(42.7 \%)$ \\
Patients $\geq 70$ y $(\mathrm{n}=355)$ & $165(46.5 \%)$ & $190(53.5 \%)$ \\
$P$ valuet & .0004 &
\end{tabular}

Data are expressed as numbers of patients with percentages in parentheses. *Including bypass operation, chemotherapy, radiotherapy, endoscopic dilation, endoscopic prosthesis placement, endoscopic laser therapy, feeding jejunostomy or gastrostomy, or any combination of these. †Surgical resection versus no surgical resection.

\section{Statistical Analysis}

Data are expressed as medians and interquartile ranges. Proportions were compared with the $\chi^{2}$ or Fisher exact test. Continuous variables were compared with the Mann-Whitney test. Survival estimates were calculated by the Kaplan-Meier method, and survival comparisons were performed with the log-rank test. Cox proportional hazard models were used to identify independent predictors of survival.

\section{Results}

Of the 1400 patients with esophageal or esophagogastric junction cancer seen at our department between January 1992 and June 2005, a total of 764 (54.6\%) underwent esophagectomy (Table 1). A significantly higher percentage of patients younger than 70 years underwent surgical resection relative to those at least 70 years old $(57.3 \%$ vs $46.5 \%$, $P=.0004)$. We excluded from further analysis 25 patients who underwent a transabdominal procedure only $(n=14)$, free jejunal transplantation $(n=1)$, myocutaneous flap reconstruction $(n=5)$, or esophageal resection without reconstruction $(\mathrm{n}=5)$. The remaining 739 patients formed the study population: $580(78.5 \%)$ patients were younger than 70 years (group A) and $159(21.5 \%)$ were at least 70 years old (group B). In the latter, elderly group, 107 (67.3\%) patients were between 70 and 74 years old, 43 (27\%) were aged 75 to 79 years, and $9(5.7 \%)$ were in their 80 s.

\section{Clinicopathologic Characteristics}

The demographic information and clinical characteristics of the patients in the two groups are summarized in Table 2. As expected, preoperative cardiovascular and respiratory risk factors were significantly more prevalent in group B. Tumor characteristics at presentation in the two groups are shown in Table 3. Tumor location and histologic type differed between the two groups, with a higher proportion of adenocarcinoma and a lower tumor location among the older patients. Table 4 summarizes the treatment details and pathologic findings at surgery. There were no significant differences in tumor stage or degree of differentiation between groups A and B. Overall, $90 \%$ of the patients were 
TABLE 2. Demographic and clinical characteristics

\begin{tabular}{|c|c|c|c|}
\hline & Patients $<70$ y $(n=580)$ & Patients $\geq 70$ y $(n=159)$ & $P$ value \\
\hline Sex (male/female) & $472 / 108$ & $124 / 35$ & .365 \\
\hline Age (y, median with interquartile range) & $59.5(53.4-64.6)$ & $73.1(71.6-76.6)$ & \\
\hline History of cardiac disease (No.) & & & $<.0001$ \\
\hline Yes & $72(12.4 \%)$ & $47(29.6 \%)$ & \\
\hline No & $508(87.6 \%)$ & $112(70.4 \%)$ & \\
\hline History of respiratory disease (No.) & & & .003 \\
\hline Yes & $87(15 \%)$ & $40(25.2 \%)$ & \\
\hline No & $493(85 \%)$ & $119(74.8 \%)$ & \\
\hline History of vascular disease (№.) & & & .0006 \\
\hline Yes & $33(5.7 \%)$ & $23(14.5 \%)$ & \\
\hline No & $547(94.3 \%)$ & $136(85.5 \%)$ & \\
\hline American Society of Anesthesiologists classification (No.) & & & $<.0001$ \\
\hline $1-2$ & $436(77 \%)$ & $91(58.7 \%)$ & \\
\hline $3-4$ & $130(23 \%)$ & $64(41.3 \%)$ & \\
\hline Data unavailable & 14 & 4 & \\
\hline Weight loss (>10\% body weight, No.) & $121(21.7 \%)$ & $27(17.4 \%)$ & .265 \\
\hline
\end{tabular}

considered to have curative resection (R0): 514 (88.6\%) of 580 in group A and 147 (92.5\%) of 159 in group B $(P=$ .191). The effects of neoadjuvant treatment in groups $A$ and $\mathrm{B}$ are shown in Table 5.

\section{Morbidity and Mortality}

Overall, the in-hospital mortality rate $2.6 \%$ (19/739): $2.7 \%$ $(16 / 580)$ among patients younger than 70 years and $1.9 \%$ (3/159) among the older patients $(P=.778)$. The overall 30-day mortality was $1.9 \%$ (14/739): $1.9 \%(11 / 580)$ in group A and $1.9 \%(3 / 159)$ in group B $(P>.999)$. The overall morbidity rate was $48.7 \%$ (360/739): $48.6 \%$ (282/ $580)$ in group A and $49.1 \%(78 / 159)$ in group B $(P=.929)$. Details of the postoperative complications in the two groups are given in Table 6 . The most common complications were pulmonary and cardiovascular, and they were more prevalent among older patients.

\section{Survival}

The median survivals were 23.1 months (interquartile range 11.8-46.4 months) for patients younger than 70 years and 17.9 months (interquartile range 9.2-44.4

TABLE 3. Tumor characteristics

\begin{tabular}{lcc}
\hline & Patients $<\mathbf{7 0} \mathbf{y}(\mathbf{n}=\mathbf{5 8 0})$ & Patients $\geq \mathbf{7 0} \mathbf{y}(\mathbf{n}=\mathbf{1 5 9 )}$ \\
\hline Histopathologic type & & $77(48.4 \%)$ \\
Squamous cell carcinoma & $372(64.1 \%)$ & $77(48.4 \%)$ \\
Adenocarcinoma & $183(31.6 \%)$ & $5(3.2 \%)$ \\
Others & $25(4.3 \%)$ & $23(29.9 \%)$ \\
History of Barrett esophagust & $50(27.3 \%)$ & $4(2.5 \%)$ \\
Tumor site & & $24(15.1 \%)$ \\
Cervical & $46(7.9 \%)$ & $37(23.3 \%)$ \\
Upper thoracic & $110(19 \%)$ & $23(14.5 \%)$ \\
Mid thoracic & $154(26.5 \%)$ & $71(44.6 \%)$ \\
Lower thoracic & $110(19 \%)$ & .763 \\
Esophagogastric junction (Siewert type I-II) & $160(27.6 \%)$ & $5(3.2 \%)$ \\
Clinical TNM stage & & $20(12.7 \%)$ \\
Stage 0 & $10(1.7 \%)$ & $71(44.2 \%)$ \\
Stage I & $70(12.1 \%)$ & $50(31.9 \%)$ \\
Stage II & $263(45.6 \%)$ & $11(7.0 \%)$
\end{tabular}

Data are expressed as numbers of patients with percentages in parentheses. TNM, Tumor-node-metastasis. *Squamous cell carcinoma versus adenocarcinoma. $†$ Analysis limited to patients with adenocarcinoma only. 
TABLE 4. Surgical treatment and pathologic findings

\begin{tabular}{|c|c|c|c|}
\hline & $\begin{array}{c}\text { Patients }<70 y \\
(n=580)\end{array}$ & $\begin{array}{l}\text { Patients } \geq 70 y \\
\text { (n }=159)\end{array}$ & $P$ value \\
\hline Neoadjuvant therapy & $214(36.9 \%)$ & $28(17.6 \%)$ & $<.0001$ \\
\hline Access & & & $.608^{*}$ \\
\hline Laparotomy + thoracotomy (right) & $373(64.3 \%)$ & $114(71.7 \%)$ & \\
\hline Thoracotomy (right) + laparotomy + cervicotomy (left) & $128(22.1 \%)$ & $21(13.2 \%)$ & \\
\hline Laparotomy + cervicotomy (left) & $79(13.6 \%)$ & $24(15.1 \%)$ & \\
\hline Reconstruction & & & $.597 \dagger$ \\
\hline Stomach & $528(91 \%)$ & $147(92.4 \%)$ & \\
\hline Colon & $41(7.1 \%)$ & $9(5.7 \%)$ & \\
\hline Other & $11(1.9 \%)$ & $3(1.9 \%)$ & \\
\hline Pathologic TNM stage & & & .598 \\
\hline Stage 0 & $62(10.7 \%)$ & $13(8.2 \%)$ & \\
\hline Stage I & $81(14 \%)$ & $25(15.7 \%)$ & \\
\hline Stage II & $177(30.6 \%)$ & $41(25.8 \%)$ & \\
\hline Stage III & $202(35 \%)$ & $62(39 \%)$ & \\
\hline Stage IV & $56(9.7 \%)$ & $18(11.3 \%)$ & \\
\hline Data not available & 2 & 0 & \\
\hline Degree of tumor differentiation $\ddagger$ & & & .831 \\
\hline Well or moderately differentiated & $421(76.3 \%)$ & $115(75.2 \%)$ & \\
\hline Poorly differentiated & $131(23.7 \%)$ & $38(24.8 \%)$ & \\
\hline Data not available & 3 & 1 & \\
\hline Resection & & & .191 \\
\hline Ro & $514(88.6 \%)$ & $147(92.5 \%)$ & \\
\hline $\mathrm{R} 1-2$ & $66(11.4 \%)$ & $12(7.5 \%)$ & \\
\hline
\end{tabular}

*Transthoracic versus nontransthoracic access. †Stomach versus colon. $\ddagger$ Data refer to squamous cell carcinoma and adenocarcinoma only.

months) for those older. Five-year survival for the whole series was $34 \%: 33.6 \%$ in group A and $35.4 \%$ in group B $(P=.257$; Figure 1$)$. When patients with R0 curative resection were considered alone, the 5-year survivals were $37 \%$ for group A and $39 \%$ for group B $(P=.279$; Figure 2). There was no significant difference in survival between male and female patients, either overall or in the age subgroups, but the 5-year survival in the older age group was higher for female patients than for male patients $(48 \%$ vs $32 \%$, difference not significant). When the older group was assessed separately, there was no significant difference

TABLE 5. Effect of neoadjuvant treatment

\begin{tabular}{|c|c|c|c|c|}
\hline & \multicolumn{2}{|c|}{ Patients $<70$ y $(n=214)$} & \multicolumn{2}{|c|}{ Patients $\geq 70$ y $(n=28)$} \\
\hline & Clinical stage* & $\begin{array}{l}\text { Pathologic } \\
\text { stage }\end{array}$ & Clinical stage $†$ & $\begin{array}{l}\text { Pathologic } \\
\text { stage }\end{array}$ \\
\hline Stage 0 & 0 & $49(22.9 \%)$ & 0 & $8(28.6 \%)$ \\
\hline Stage I & $4(1.9 \%)$ & $19(8.9 \%)$ & 0 & $3(10.7 \%)$ \\
\hline Stage II & $63(29.7 \%)$ & $72(33.6 \%)$ & $3(11.1 \%)$ & $10(35.7 \%)$ \\
\hline Stage III & $120(56.6 \%)$ & $52(24.3 \%)$ & $18(66.7 \%)$ & $5(17.9 \%)$ \\
\hline Stage IV & $25(11.8 \%)$ & $22(10.3 \%)$ & $6(22.2 \%)$ & $2(7.1 \%)$ \\
\hline
\end{tabular}

Data are expressed as numbers of patients with percentages in parentheses. *Data not available for 2 patients. $†$ Data not available for 1 patient. in 5-year survival between patients 70 to 74 years old and those at least 75 years of age.

Details of univariate analysis of survival are shown in Table 7. Cox multivariate analysis identified tumor stage, histologic type, and degree of differentiation as independent predictors of long-term survival (Table 8).

\section{Discussion}

Some important observations emerge from this study. First, with current advances in surgical management and perioperative care, elective esophagectomy can be safe even in elderly patients with medical risk factors if the tumor is amenable to surgical resection. Second, long-term survival for elderly patients is comparable with that of younger patients.

Worldwide increase in the elderly population in the last decades has made surgeons face the everyday dilemma of whether to perform major surgery on an elderly patient. The need for digestive tract surgery for patients at least 70 years old is becoming a serious and crucial health problem in Western countries. There have been advances in the multimodal management of many digestive tract cancers in the last 3 decades, but for many of them-esophageal cancer in particular-surgery remains the mainstay of treatment. Undoubtedly, esophagectomy is a major surgical procedure, 
TABLE 6. Morbidity and mortality

\begin{tabular}{|c|c|c|c|}
\hline & Patients $<70$ y $(n=580)$ & Patients $\geq 70$ y $(n=159)$ & $P$ value \\
\hline \multicolumn{4}{|l|}{ Mortality } \\
\hline In hospital & $16(2.7 \%)$ & $3(1.9 \%)$ & .778 \\
\hline At $30 \mathrm{~d}$ & $11(1.9 \%)$ & $3(1.9 \%)$ & $>.999$ \\
\hline \multicolumn{4}{|l|}{ Complications } \\
\hline Pulmonary (pneumonia, atelectasis, lung failure) & $89(15.3 \%)$ & $27(17 \%)$ & .623 \\
\hline $\begin{array}{l}\text { Cardiovascular (myocardial infarction, severe arrhythmia, } \\
\text { pulmonary edema, pulmonary embolism) }\end{array}$ & $29(5 \%)$ & $15(9.6 \%)$ & .056 \\
\hline \multicolumn{4}{|l|}{ Other } \\
\hline Chylothorax & $10(1.7 \%)$ & 0 & .130 \\
\hline Laryngeal nerve palsy & $46(7.9 \%)$ & $12(7.5 \%)$ & $>.999$ \\
\hline Anastomotic leak or graft necrosis & $53(10.2 \%)$ & $12(7.5 \%)$ & .636 \\
\hline Hemorrhage & $4(0.7 \%)$ & $3(1.9 \%)$ & .174 \\
\hline Renal failure & $5(0.9 \%)$ & 0 & .59 \\
\hline Wound infection & $10(1.7 \%)$ & $1(0.6 \%)$ & .472 \\
\hline Reoperations & $20(3.4 \%)$ & $4(2.5 \%)$ & .800 \\
\hline
\end{tabular}

Data are expressed as numbers of patients with percentages in parentheses.

and its high postoperative morbidity and mortality are well recognized. Nonetheless, improvements in perioperative care and recent studies reporting much the same morbidity and mortality rates among elderly patients undergoing esophageal resection as among their younger counterparts have prompted a reassessment of the true effect of age on the outcome of esophagectomy for esophageal cancer.

The idea that older age itself contraindicates major surgery such as esophagectomy seems to be a misconception. Of course, careful preoperative risk assessment is important in selecting patients for esophagectomy. A significant number of our elderly patients had preoperative cardiovascular or pulmonary dysfunction and similarly had cardiopulmonary complications in the postoperative period. Pulmonary complications were among the most frequent causes of morbidity among both younger and older patients, which

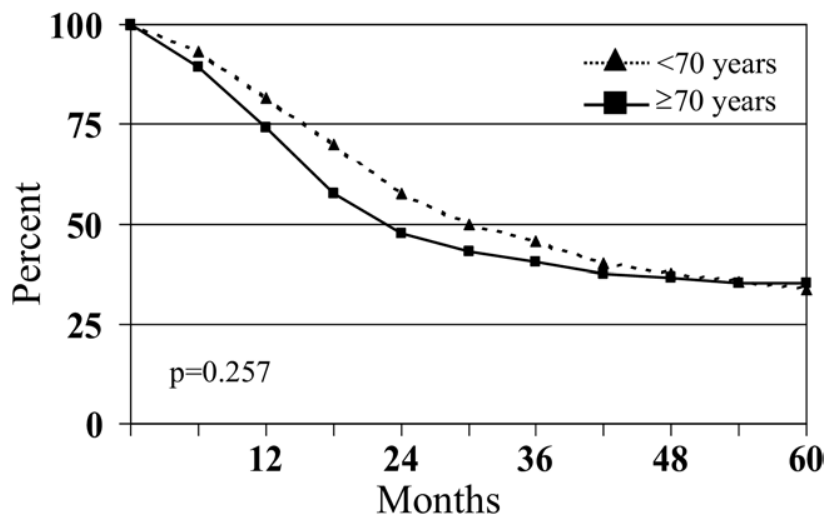

Figure 1. Kaplan-Meier survival curves (including postoperative deaths) plotted for patients younger than 70 years versus patients 70 years old and older, all resections $\left(\chi^{2}=1.286, P=.257\right)$. emphasizes the importance of frequent bronchoscopic suctioning and incentive spirometry before and after the operation, performed routinely by patients or preferably by a respiratory therapist.

The mortality did not differ significantly between our two age groups, and there are several factors responsible for this result. First is greater experience ${ }^{1,8}$ and refinement in surgical technique: all esophagectomies were performed by the same team of surgeons specializing in esophageal surgery. Improved perioperative patient care has also contributed to reduce related morbidity (especially pulmonary complications) and mortality. Most of all, postoperative epidural analgesia for better pain control and less interference with pulmonary mechanics has helped, along with incentive spirometry, to improve postoperative lung activity. ${ }^{9}$

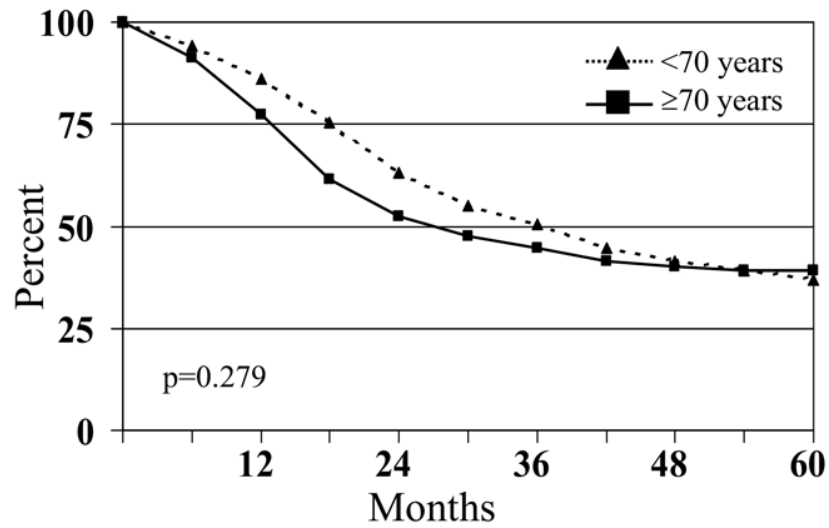

Figure 2. Kaplan-Meier survival curves (including postoperative deaths) plotted for patients younger than $\mathbf{7 0}$ years versus patients 70 years old and older, $\mathrm{RO}$ resections only $\left(\chi^{2}=1.169, P=.279\right)$. 
TABLE 7. Univariate analysis of survival

\begin{tabular}{lcc}
\hline & 5-y survival (\%) & $\boldsymbol{P}$ value \\
\hline Age (y) & & .26 \\
$\quad<70$ & $33.6 \%$ & \\
$\geq 70$ & $35.4 \%$ & \\
Sex & & .177 \\
$\quad$ Male & $33.3 \%$ & \\
$\quad$ Female & $36.6 \%$ & \\
Tumor location & & .52 \\
$\quad$ Cervical, upper thoracic, mid thoracic & $32.2 \%$ & \\
$\quad$ Lower thoracic, esophagogastric & $36 \%$ & \\
$\quad$ junction (Siewert type I-II) & & \\
Histologic type & & .15 \\
$\quad$ Squamous cell carcinoma & $32.1 \%$ & \\
$\quad$ Adenocarcinoma & $38 \%$ & \\
Neoadjuvant therapy & & .38 \\
$\quad$ Yes & $36 \%$ & \\
$\quad$ No & $33 \%$ & \\
Pathologic TNM stage & & $<.0001$ \\
$\quad$ Stage 0, I, or II & $49.5 \%$ & \\
Stage III or IV & $15.3 \%$ & \\
Degree of tumor differentiation & & \\
$\quad$ Well or moderately differentiated & $36.6 \%$ & \\
Poorly differentiated & $26.7 \%$ & \\
\hline
\end{tabular}

Keeping in mind the previously mentioned results, we need to remember that they were obtained in a selected population of elderly patients. A significantly higher proportion of patients 70 years of age or older did not undergo surgery than their younger counterparts. When we analyzed the reasons for exclusion from surgery (data not shown), we found out that nearly $40 \%$ of elderly patients were excluded for comorbidity-related reasons; this cause accounted for fewer than $20 \%$ of exclusions of surgery among the younger subjects.

The reported 5-year survival after resection for esophageal carcinoma is in the $15 \%$ to $20 \%$ range, ${ }^{10,11}$ a fact that has raised concerns regarding the advisability of such an extensive procedure as esophagectomy in elderly patients. ${ }^{12,13}$ Palliative treatments have been advocated as the sole treatment option for such patients, although it is well known that the median survival after palliation is only 4 months. The overall 5-year survival in our series was more than $34 \%$. What is more, there was no significant difference between older and younger patients. As shown previously, $2,7,14-15$ if elderly patients can survive the esophagectomy itself, then the 5-year survival is independent of age. When we analyzed the long-term results of our at least 75-year-old patients, they fared just as well as their younger counterparts, if not better.

Interestingly, we didn't find any significant difference in overall survival between male and female patients, and we interpreted the loss of prognostic effect of female sex as
TABLE 8. Multivariate analysis of predictors of survival

\begin{tabular}{lll}
\hline & $\chi^{2}$ & $P$ value \\
\hline Age group ( $\geq 70$ y) & 2.41 & .12 \\
Sex (male) & 2.62 & .11 \\
Tumor location (upper site) & 0.7 & .4 \\
Neoadjuvant therapy (none) & 0.09 & .76 \\
Histologic type (squamous) & 7.89 & .005 \\
Degree of tumor differentiation (poor) & 3.92 & .048 \\
Tumor stage (p III-IV) & 97 & $<.0001$ \\
\hline
\end{tabular}

*Upper sites include cervical, upper thoracic, and mid-thoracic tumor locations.

probably the result of a higher percentage of esophageal squamous cell carcinoma among female patients than among male patients. This study was not designed to assess the relationship between sex, histologic type, and survival, however, and such will require further detailed analysis of our data.

Esophageal resection not only restores swallowing function, which means restoration of a decent quality of life, but it also gives patients a chance of cure. In other words, it is worthwhile. This study did not intend to assess the details of each single prognostic factor for survival among patients undergoing esophagectomy for esophageal cancer, but a review of the 739 esophagectomies included in this series, performed at our institution during the last 14 years, showed that older age did not affect long-term survival.

It is important to remember when discussing the results of this study that they were achieved in a specialized center for esophageal diseases. It is now widely recognized that certain high-risk surgical procedures have lower mortality and morbidity as well as better outcome when performed in high-volume centers. ${ }^{16,17}$ This is specifically true for esophageal cancer surgery, with individual surgeon experience, expert team assistance, and access to better infrastructure resources to manage critically ill patients all playing a determinant role.

In summary, increased surgical experience and refinements in perioperative care can explain the improved results achieved with esophagectomy in elderly patients in recent years. Short- and long-term outcomes after esophagectomy for carcinoma in patients 70 years old or older are equivalent to those of their younger counterparts. Advanced age per se thus should not be considered a contraindication to esophageal resection. For selected patients who are fit for surgery and have resectable lesions, esophagectomy is indicated and worthwhile, regardless of age. A careful selection of candidates for surgery is mandatory, however, to keep morbidity and mortality to acceptable levels and achieve much the same long-term survival for younger and older patients. 


\section{References}

1. Poon R, Law SY, Chu KM, Branicki GJ, Wong J. Esophagectomy for carcinoma of the esophagus in the elderly. Ann Surg. 1998;227: 357-64.

2. Adam DJ, Craig SR, Sang CT, Cameron EJ, Walker WS. Esophagectomy for carcinoma in the octogenarian. Ann Thorac Surg. 1996;61: 190-4.

3. Ferguson MK, Martin TR, Reeder LB, Olak J. Mortality after esophagectomy: risk factor analysis. World J Surg. 1997;21:599-604.

4. Bonavina L, Incarbone R, Saino G, Clesi P, Peracchia A. Clinical outcome and survival after esophagectomy for carcinoma in elderly patients. Dis Esophagus. 2003;16:90-3.

5. Rahamin JS, Murphy GJ, Awan Y, Junemann-Ramirez M. The effect of age on the outcome of surgical treatment for carcinoma of the oesophagus and gastric cardia. Eur J Cardiothorac Surg. 2003; 23:805-10

6. Ellis FH, Williamson WA, Heatley GJ. Cancer of the esophagus and cardia: does age influence treatment selection and surgical outcomes. J Am Coll Surg. 1998;187:345-51.

7. Merigliano S, Ruol A, Baldan N, Santi S, Petrin GF, Polo R, et al. Management and prognosis of esophageal cancer in elderly patients. J Chemotherapy. 1996;8:72-4.

8. Kinugasa S, Tachibana M, Yoshimura H, Dhar DK, Shibakita M, Ohno S, et al. Esophageal resection in elderly esophageal carcinoma patients: improvement in postoperative complications. Ann Thorac Surg. 2001;71:414-8.

9. Shulman M, Sandler AN, Bradley JW, Young PS, Brebner J. Postthoracotomy pain and pulmonary function following epidural and systemic morphine. Anesthesiology. 1984;61:569-75.

10. Muller JM, Erasmi H, Stelzner M, Zieren U, Pichlmaier H. Surgical therapy of esophageal carcinoma. Br J Surg. 1990;77:845-57.

11. Daly JM, Karnell LH, Menck HR. National Cancer Data Base report on esophageal carcinoma. Cancer. 1996;78:1820-8.

12. Nozaki M, Murakami Y, Furuta M, Izawa Y, Iwasaki N. Radiation therapy for cancer in elderly patients over 80 years of age. Radiat Med. 1998;16:491-4.

13. Barr H, Krasner N, Raouf A, Walker RJ. Prospective randomized trial of laser therapy only and laser therapy followed by endoscopic intubation for the palliation of malignant dysphagia. Gut. 1990;31:252-8.

14. Sugimachi K, Matsuzaki K, Matsuura H, Kuwano H, Ueo H, Inokuchi $\mathrm{K}$. Evaluation of surgical treatment of carcinoma of the esophagus in the elderly: 20 years' experience. Br J Surg. 1985;72:28-30.

15. Naunheim KS, Hanosh J, Zwischenberger J, Turrentine MW, Kesler KA, Reeder LB, et al. Esophagectomy in the septuagenarian. Ann Thorac Surg. 1993;56:880-4.

16. Chang AC, Birkmeyer JD. The volume-performance relationship in esophagectomy. Thorac Surg Clin. 2006;16:87-94.

17. Casson AG, JJ Van Lanschot. Improving outcomes after esophagectomy: the impact of operative volume. J Surg Oncol. 2005;92:262-6.

\section{JTCVS On-Line Manuscript Submission and Review}

The Journal of Thoracic and Cardiovascular Surgery requires authors and reviewers to submit all new and revised manuscripts and reviews via Editorial Manager. Point your browser to http://jtcvs.editorialmanager.com, log in as author or reviewer (as appropriate), and follow the instructions provided.

To retrieve your username and password, click "Forget your password?" on the Editorial Manager log-in page.

If you have questions or experience problems uploading your manuscript or review, please contact the editorial office:

Telephone: $215-762-1854$

E-mail: jtcvs@drexelmed.edu 